Supplement of Biogeosciences, 13, 3519-3531, 2016

http://www.biogeosciences.net/13/3519/2016/

doi:10.5194/bg-13-3519-2016-supplement

(C) Author(s) 2016. CC Attribution 3.0 License.

(c) (i)

Supplement of

\title{
Tracer experiment and model evidence for macrofaunal shaping of microbial nitrogen functions along rocky shores
}

\section{A. Pfister et al.}

Correspondence to: Catherine A. Pfister (cpfister@uchicago.edu)

The copyright of individual parts of the supplement might differ from the CC-BY 3.0 licence. 
Figure S1. Example dynamics of stable nitrogen isotopes $\left(\delta^{15} \mathrm{~N}\right)$ of tidepool ammonium, nitrite and nitrate for 4 separate ${ }^{15} \mathrm{~N}$ enrichment experiments made at different times in a single control tidepool (with mussels). We measured values prior to the addition of tracer $\left(\mathrm{T}_{\mathrm{o}}\right)$, followed by an immediate post-tracer measurement $\left(\mathrm{T}_{1}\right)$, and an approximately 2-3 hour $\left(\mathrm{T}_{2}\right)$ and a 5-6 hour $\left(\mathrm{T}_{3}\right)$ post-tracer measurement. The left 2 panels show the addition of enriched ammonium and the resultant nitrate and nitrite enrichment, while the right 2 panels show the addition of enriched nitrate and the resultant enrichment in ammonium and nitrite. In all cases, the $\delta^{15} \mathrm{~N}(\%)$ axis scale for the enriched source is double that of the product quantities. 
Figure S1

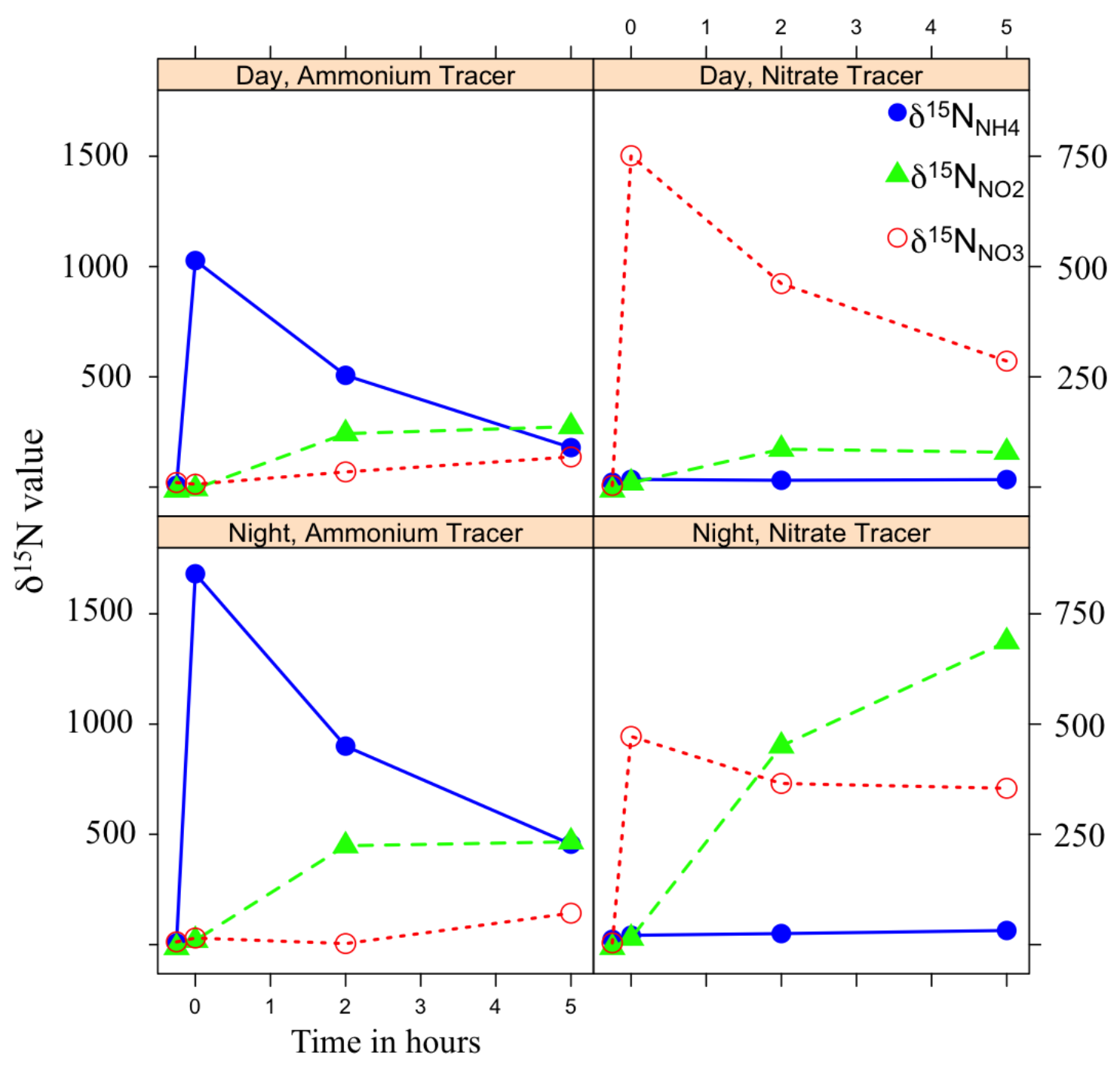


Figure S2. We show the fit of models (colored lines) to data (points) where we varied the ratio of $u$ for ammonium uptake versus nitrate uptake for a single tidepool during a daytime, ammonium enrichment. This representative scenario shows that a 2:1 ratio, where phototrophic ammonium uptake is twice that of nitrate uptake, was the best fitting model. Greater or lesser ratios did not fit the data as well. Other figure attributes as in Fig 3.
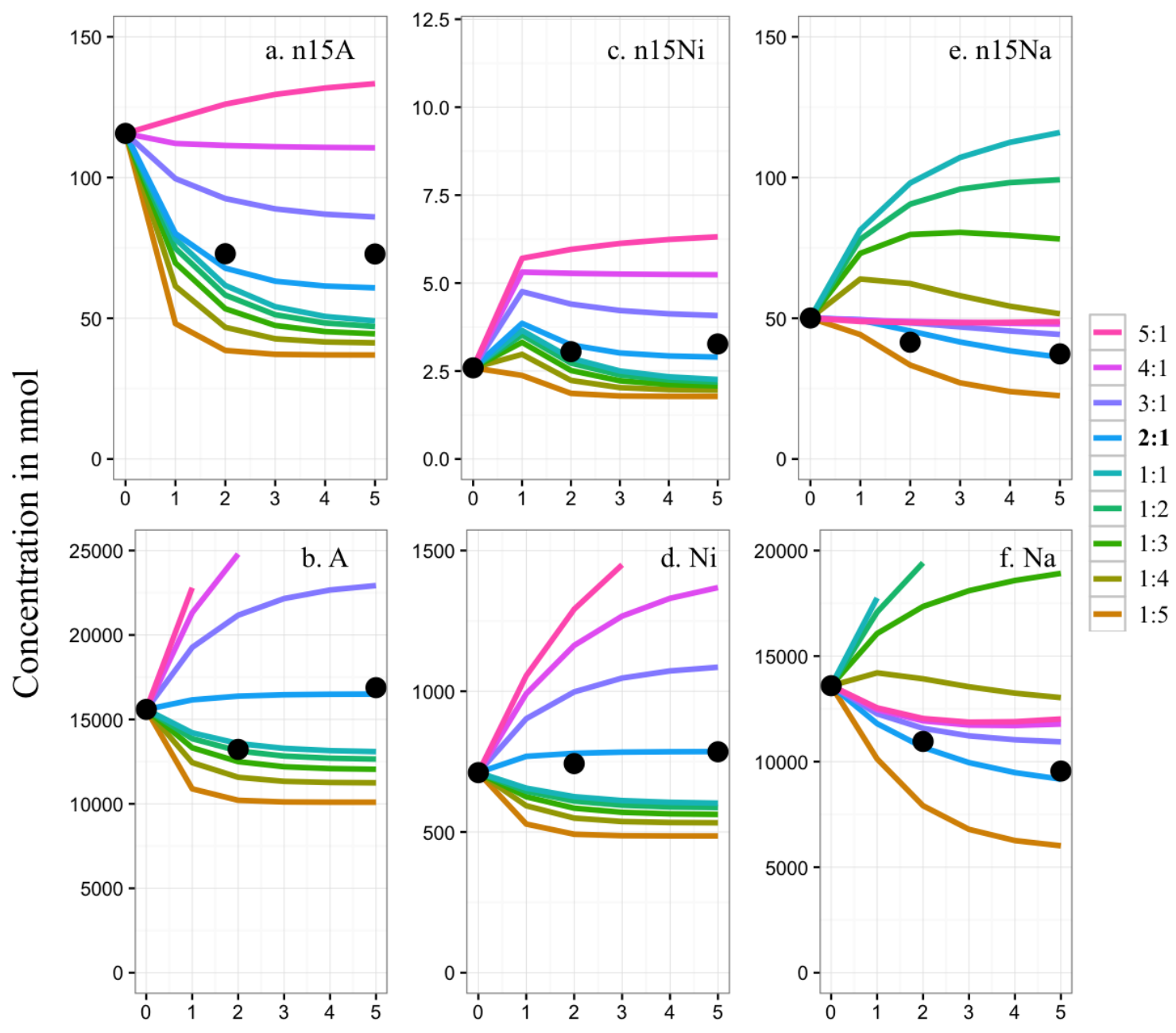

Time in hours 